\title{
Assessment of Stakeholders' Organizational Readiness to Interact in the Uncertain Milieu of a Municipal Entity
}

\author{
Grigory Nikiforovich Donchevsky ${ }^{1}$, Nina Aleksandrovna Ustina ${ }^{2}$ \& Anna Aleksandrovna Karlina ${ }^{2}$ \\ ${ }^{1}$ Southern Federal University, Rostov-on-Don, Bolshaya Sadovaya Str., 105/42, Russian Federation \\ ${ }^{2}$ Samara Academy of state and municipal management, Samara, Stara Zagora Str, 96, Russian Federation \\ Correspondence: Grigory Nikiforovich Donchevsky, Southern Federal University, Rostov-on-Don, 344006, \\ Bolshaya Sadovaya Str., 105/42, Russian Federation. E-mail: dongrin@yandex.ru
}

\author{
Received: August 13, 2014 Accepted: August 23, 2014 Online Published: November 27, 2014 \\ doi:10.5539/ass.v10n24p103 \\ URL: http://dx.doi.org/10.5539/ass.v10n24p103
}

\begin{abstract}
The subject of the research shows itself as the organizational mechanisms of forming the interactive context for stakeholders within the uncertain milieu of the municipal entity. The goal of the research is reasoning of the evaluation model of organizational characteristics of the interacting agents that determines their activity in the city development processes. As a result of the research evaluation model of local authorities' efforts on organization of interaction of city development subjects was built. The research application is the management of complex programs and strategy of municipal institutions. In the conclusion there are defined the ways of local authorities' management organization on activation of new sources of city development, including development of interaction milieu for a priori undefined and administratively independent parties concerned.
\end{abstract}

Keywords: local authorities, city development management, interaction of the parties concerned

\section{Introduction}

The management of the city's socio-economic development process demands a building of special forms organization of local authorities work on complex municipal programs and strategies realization (An, n. d.). New approaches to the socio-economic development organization could be found in a problem domain which includes absolute limitation of the resources which are available to the management subject (i.e. local authorities), and necessity of new technologies for development sources activation beyond the organizational bounds, authorities and sphere of direct administrative influence of these subjects.

The goal of the research is reasoning of the evaluation model of organizational characteristics of the interacting agents that determines their activity in the city development processes. Possibilitica paradigm proposed by G. N. Donchevsky became a theoretical basis for creation of new organizational mechanisms of city development management. Possibilitica grows from theoretical perception of a deep system crisis which was caused by the transition of humans' economy from the state of relative limitation of resources (that it was a motivation for development) to absolute limitation (that makes economic activity impossible as such). Possibilitica paradigm moves participants from narrow bounds of limited resources to a milieu of unlimited possibilities which fulfills ordinary existence (Donchevsky, 2011, p. 29).

New angle of the research of interaction processes in socio-economic space demands establishing of organizational and management models providing economic usage of such additional development sources as territorial and people's possibilities. The methodology of such models building was proposed in milieu approach (Interdisciplinary problems of environment approach to the innovative development, 2011).

\section{Method}

\subsection{Milieu Approach in the Organization of Stakeholders' Interaction}

According to the milieu approach municipal formation is considered as an interaction milieu of different administratively independent agents participating local development. Milieu approach to local development management assumes that local authorities indirectly (through the milieu forming) affect interaction of the economy units which participate the creation of socially significant values (Partushev, 2008).

In the practice of municipal management the purpose of the possibilitical interaction milieu is arrangement of 
conditions for extra sources activation for realization of complex programs and strategies of municipal development.

Milieu approach has its own characteristics within the classical systems approach to management of social and economic development of the territory. It shifts the emphasis in managerial activities from the objects and subjects, which the system operates, to the system on inter-subject relationships based on milieu approach foundation of relations between entities around value creation. Originally, the synergy introduced the concept of self-organizing active nonlinear milieu, but in the framework of synergy, the self-organizing milieu was considered from the point of view of classical rationality. (Voytsehovich, 2011) The milieu approach deals with value orientations of subjects that determine the content and result of interaction.

Application of the milieu paradigm in managing the development of the municipal entity requires radical changes in relation to its role in the process of urban policies and integrated programs implementation from local governments, local communities, business entities, project and business communities.

Managerial activities for the implementation of integrated regional development programs should be seen in arranging the stakeholders interaction milieu, in order to saturate the strategic initiatives with the funding sources. The process of organizing collaboration environment is viewed as a value-orientation (definition of the organizer's set of values), as the definition of the problem field in which the processes of the territory development are deployed, the formation of the information space, the saturation of space with situations that are problematic for implementing of targeted programs, project initiatives. The result of the situation is seen in contracts and creating of organizational forms, which activate the additional sources of comprehensive programs and strategies.

Elements of the milieu approach in organizing the stakeholders' interaction are currently reflected, in particular, in the development and implementation of strategies in the city district Samara, they are also being realized in the model of initiatives' management in the settlement Gukovo, Rostov region (Donchevsky et al., 2011).

The peculiarity of the proposed management models of territorial development lies in their openness for stakeholders, who are, at any stage, able to offer their projects for implementation. They are also quite clearly shaped in organizational forms, to implement the whole complex of program activities and strategic initiatives. At the same time, these models have not yet elaborated the criteria and indicators of the administration organizational readiness to ensure the promotion of project initiatives, to create conditions in order to saturate the strategic initiatives with additional sources for their implementation.

To develop the criteria and assessment model of the administration efficiency in creating the interaction milieu, we need to justify the characteristics of this milieu. Studies on the milieu approach consider the concept of usual reflective-active milieu (Lepskiy, 2010). Activity and reflection are displayed as the main features of the milieu. At the same time, viewing the features of interaction milieu for subjects of different nature with the help of the possibilitary approach, we add such properties as uncertainty and uniqueness to the existing ones.

\subsection{The Main Characteristics of the Milieu Approach of Stakeholders}

The basic characteristics of the possibilitical milieu are: uncertainty, uniqueness and organization. The idea of ucertainty as the characteristic of interaction milieu is fundamental in modern theory of organizations' building. With reference to the activation processes this term was proposed by F. Knight (Knight, 2003, p.204). Following F. Knight the most part of scientists describes uncertainty as an initial state of processes that actualize creation of legal, infrastructural, financial links which return controllable systems to the equilibrium state (Brouwer, 2000), i.e. links that reduce uncertainty.

At the same time possibilitica proposes to use uncertainty to get access to the participant's possibilities. Interaction agents' uncertainty in possibilitical milieu is conditioned by their administrative independence, uniqueness and complex system of individual choices which define their readiness for interaction not in the source space but in possibilitical space.

Readiness of local authorities to supply possibilitical interaction milieu is defined by their ability to work under uncertain conditions without reduce them but using them to get access to latent abilities of territory and people. Mechanism for the usage of uncertainty and getting access to the abilities is a game. This mechanism has fundamental difference from traditional ways of organization of interaction concerning resources (transaction, exchange), which are built on the base of alienation and appropriation processes, calculation of profit and risks. Interaction on possibilities (i.e. gaming) realizes by alienation based on estimate of a gain. Possibilities gaming in the interaction process provide agents' access to the gain. The estimates of the gain unlike the profit are a priori unknown, cannot been calculated and are unique for every interaction participant. 
Using uncertainty to get access to unpredictable gain is peculiarity of entrepreneurial behavior. Marking out distinctive feature of entrepreneurship well-known American sociologist D. Stark wrote: "Entrepreneur is repaid not for taking risks but for uncertainty usage" (Stark, 2009, p. 13).

The local authorities', citizens' readiness for activity under conditions of uncertainty reflected in Appendix A. Dynamics of these indicators shows the ability of interaction agents to organize possibilitical milieu and activate extra sources of city development.

The main source of uncertainty in possibilitical milieu is uniqueness of interaction process. Yet in the beginning of the $20^{\text {th }}$ century J. Schumpeter, defining entrepreneur as the main actor of economic development process, emphasized that only entrepreneurs, who are the carriers of unique creative abilities, demonstrate readiness for new ideas realization in uncertain milieu which is generated by their lack of knowledge about the gain in the result of interaction (Schumpeter, 1995).

Possibilitica concentrates on unique, unpredictable side of the processes of extra sources activation for the purpose of realization of complex programs and strategies. In modern researches uniqueness is recognized and considered as category specifying special level of milieu organization that is mesolevel (Kleyner, 2011). Mesolevel is considered in the context of behavior of enterprises, organizations, households, i.e. subjects of various nature. It is formed as a result of agents' mutual targeting based on "named" personalized interaction.

Results of possibilitical interaction are caused not by rational strategy planning but by individual trajectories of economic activities (Koenig, 2010, pp. 120-124). Access to unique values raises activity of economic agents, their readiness for alienation and activation of extra latent development sources (Rifkin, 2000).

Valuable indicators (Appendix A) for evaluation of citizens' readiness for alienation to get access to unique impressions in our opinion are dynamics of demand for paid cultural and entertain events and increase of expenditures for additional education in households' budget.

The task of uncertainty usage for unique values creation and getting access to agents' possibilities issues the challenge for local authorities about possibilitical milieu organization. Milieu approach assumes transition from fragmental structuring to organization of interaction space. G. P. Shchedrovitskiy gives the term "organization" as a special state of interaction milieu that is defined not by bonds but by relations (Schedrivitsky, 2003). Its main difference from structure is absence of rigid connections between elements when any bond's break causes the whole system unbalancing.

Modern level of researches over organizations development allows to consider not only organizations' flexibility as the main factor of adaptation but also creation of fundamentally new interaction forms that totally destroy bounds of traditional organizations and use uncertainty to get access to possibilities.

Management effort of local authorities in the line of creation of new organizations during the interaction process is reflected in dynamics of autonomous institutions' creation, transition of municipal services and functions to outside firms (Tarasov et al., 2011), in forms variety of organization and placing of municipal orders.

\section{Results}

Citizens' ability and readiness to communicate in the purpose of getting access to unique values and creating organizations in the economic space are reflected in developing of volunteer groups (for example, volunteer auxiliary police), house owners associations, peoples' entrepreneurial activity, activity of civil society organizations (Yang \& Callahan, 2007). These indicators (Appendix A) demonstrate civilians' comprehension of their own active role in getting access to the municipal values based on unique notions about these values content and quality.

According to considered theoretical approaches authors built an evaluation model of development level of interaction milieu in the city's society during the process of socially significant values creation. This model was based on statistic indicators used particularly in the annual mayors' reports (The Decree of Government of Russian Federation, 2008).

The model includes a list of indicators defining agents' positions, used management technologies and existent organizational forms of interaction at the city's territory (Appendix A). These indicators reflect such general characteristics of the possibilitical interaction milieu as organization, uncertainty and uniqueness.

All the indicators were collected in three groups (Appendix A). Two first groups join indicators that reflect municipal agents' activities in possibilitical milieu.

The third group of indicators reflects the impact of the municipal entities' activities in order to enhance the additional sources of territorial development. They are not just generalized indicators of social and economic 
state. They reflect immediate effects of possibilitical interaction milieu and the process of extra sources activation for local development.

The valuation of the readiness level of municipal agents for activity under uncertainty conditions, as well as effectiveness of this process from in regard to socio-economic development was given using comparative analysis of some municipal formations' indicators of 2012.

There were used generalized indicators: fractional rank, generalized state indicator, average generalized state indicator.

Fractional rank shows the value of particular indicator. It can be calculated using one of two formulas:

a) when greater value of indicator means greater effectiveness:

$$
\operatorname{Irh}=\frac{(\text { Ac }- \text { Min })}{(\text { Max }- \text { Min })}
$$

where $A c$ is the value of municipal indicator for the reporting year; Max and Min accordingly are maximal and minimal values of the indicator from the group.

b) when greater value of indicator means less effectiveness:

$$
\operatorname{Irh}=\frac{(\operatorname{Max}-A c)}{(\operatorname{Max}-\operatorname{Min})}
$$

Generalized state indicator (Ir) is calculated using the following formula:

$$
\operatorname{Ir}=\sum(\operatorname{Irh} \times W)
$$

where $I r h$ is particular municipal index in the given sphere; $W$ is unit weight of the effectiveness indicator in the given sphere.

Unit weight of the indicator in the given sphere is calculated by the formula:

$$
W=\frac{1}{N}
$$

where $N$ is amount of effectiveness indicators in the given sphere.

The sample for statistical analysis includes municipal formations from Samara, Rostov and Krasnodar Regions. Sampling was accomplished under the following criteria:

1) the sample should represent different types of regions (recipient and donor, agricultural and industrial);

2) presence of the common indicators for comparison (territorial and geographic proximity, average quality of life, competiveness level);

3) existence of enough amount of cities in the region;

4) availability of the same statistic data.

The purpose of the analysis was detection of the following regularities:

5) response of development level of possibilitical milieu of municipal agents' interaction from purposeful organizational and management effort of local authorities;

6) influence of the development of possibilitical interaction milieu on the main indicators of social and economic municipal development.

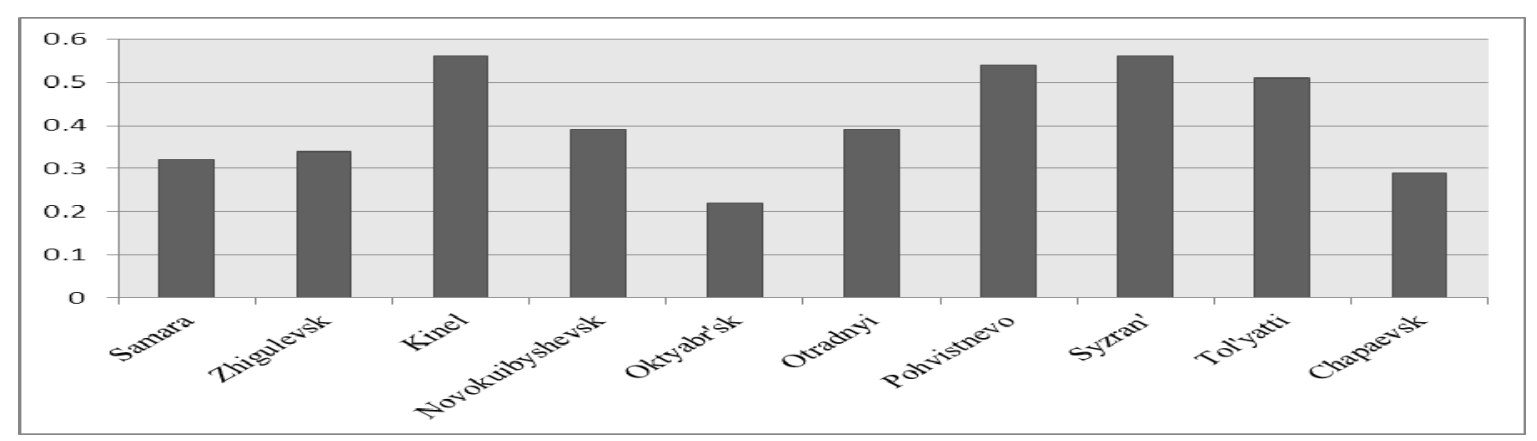

Figure 1. Development level of possibilitical interaction milieu in the cities of the Samara region 
Development level of interaction processes in accordance to specified regions is shown on the figures 1-3. Interaction of the three groups of indicators showing the possibilitical milieu development is demonstrated on the Figures 4-6.

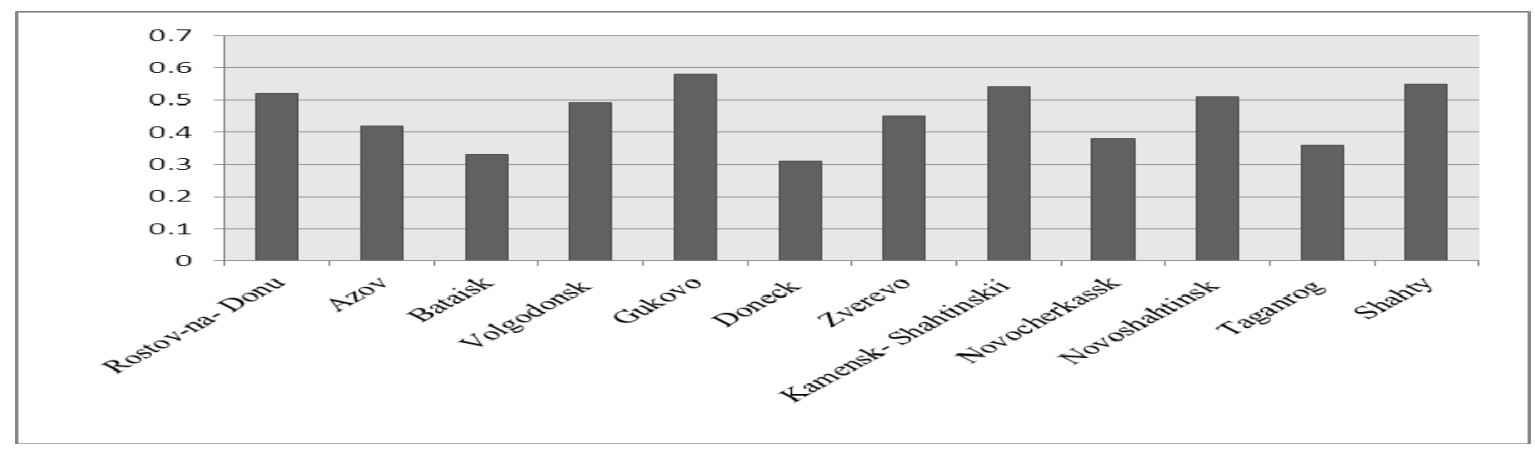

Figure 2. Development level of possibilitical interaction milieu in the cities of the Rostov region

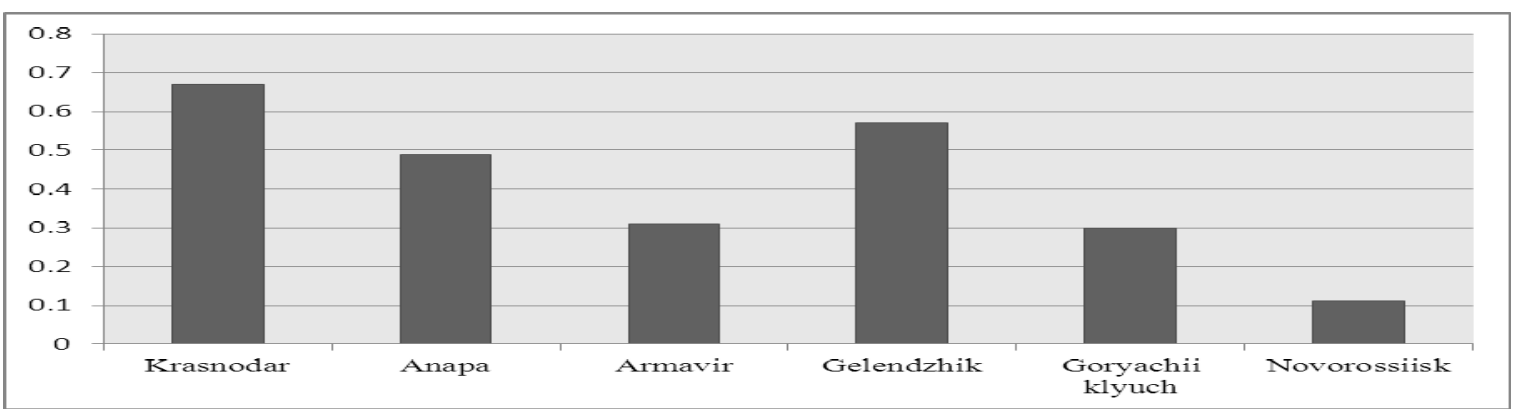

Figure 3. Development level of possibilitical interaction milieu in the cities of the Krasnodar region
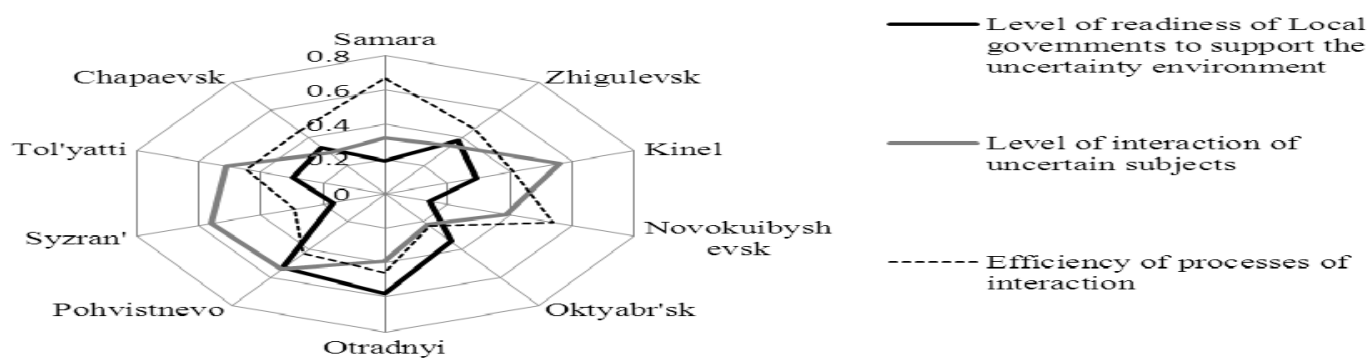

Figure 4. Correlation of development indicators of possibilitical interaction milieu in the cities of Samara region

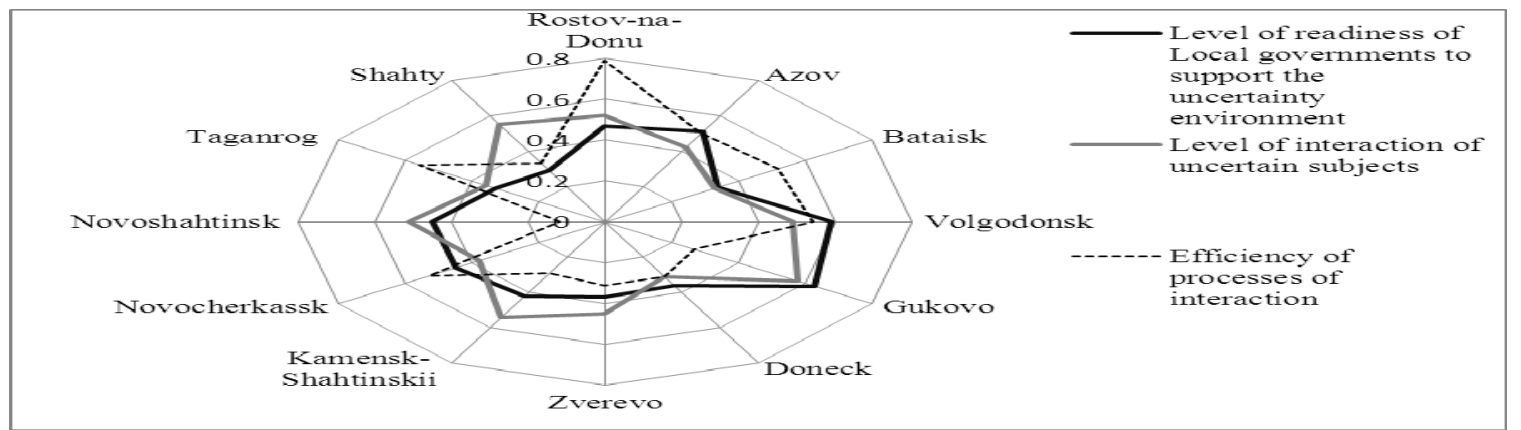

Figure 5. Correlation of development indicators of possibilitical interaction milieu in the cities of Rostov region 


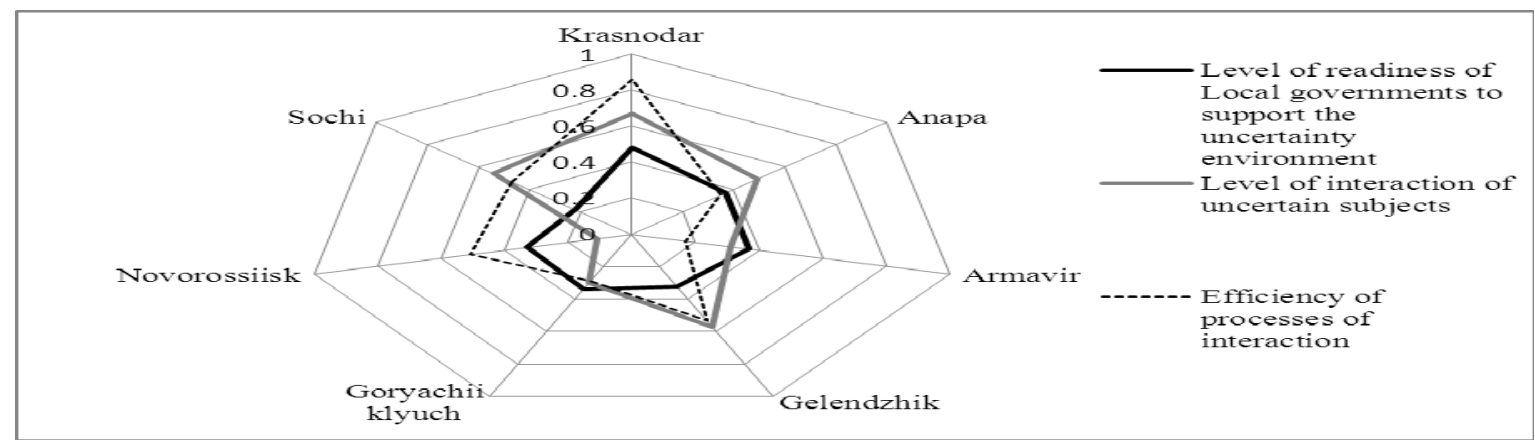

Figure 6. Correlation of development indicators of possibilitical interaction milieu in the cities of Krasnodar region

\section{Discussion}

The analysis allows finding out the following groups of the cities:

$1^{\text {st }}$ group: cities where all three groups of indicators have same tendency, to be exact: the level of interaction of municipal agents and local authorities' effort has response and results in the indicators of socio-economic development. This group includes the following cities: Goryachy Klyuch, Anapa (Krasnodar Region); Pokhvistnevo, Oktyabrsk, Zhigulyovsk (Samara Region); Donetsk, Azov, Vologodonsk, Zverevo, Novocherkassk (Rostov Region).

$2^{\text {nd }}$ group: cities where the socio-economic development indicators are mainly influenced by active efforts of local authorities on creation of favorable interaction milieu but not by the milieu itself. This group includes: Novorossiysk (Krasnodar Region); Otradny, Chapaevsk (Samara Region).

$3^{\text {rd }}$ group: cities where socio-economic development indicators are mainly influenced by active position of local associations on forming of interaction milieu. They include: Gelendzhik, Sochi, Krasnodar (Krasnodar Region), Tolyatti, Novokuybyshevsk, Kinel (Samara Region).

$4^{\text {th }}$ group: cities where interaction environment of local authorities and local associations has no significant effect on the level of socio and economic development of the territory. They are: Armavir (Krasnodar Region); Samara (Samara Region); Gukovo, Kamensk-Shakhtinsky, Novoshakhtinsk, Taganrog, Rostov-on-Don (Rostov Region). Accordingly in this group could be separated two subgroups:

- cities where high values of indicators of local authorities and local associations effort on possibilitical milieu creation do not provide high level of socio-economic indicators;

- cities where high level of socio-economic indicators are not related with the same high level of development of possibilitical interaction milieu.

The $4^{\text {th }}$ group is the most complicated for estimation of influence of the milieu development level on the local development. As a conjecture, which proof is outside of this research, there may be some other factors on the territory (solid endogenous investments, exogenous factors of deep territorial depression etc.).

However, the most of researched cities (70\%) show the influence of at least one factor of the interaction milieu development influence on the indicators of the local socio-economic development.

Special problem of the research is the problem of a mutual reference of the $1^{\text {st }}$ and $2^{\text {nd }}$ groups of indicators which is how far do indicators of the local society's interaction milieu development depends on the activities of local authorities on this milieu creation. Such dependence was found out in 18 cities $(62 \%)$.

This differentiation of cities by groups of factors affecting the level of socio-economic development is linked with the problem of cities' capitalization, which is widely discussed in the research literature (Turner, 2000; Social Capital, 2000; Lin, 2000). The notion "capitalization" is seen in this case as "the growth of the value of assets within its territory" (Features of regional capital reproduction, 2008, p. 84). Among the factors of capitalization they allocate physical, human, information, administrative and other types of assets, providing the city capitalization. The role of human capital deserves the particular attention for the territory development (Khmeleva, 2012, p. 49).

Basing on this study, we can assume that the cities of the first group differ in the development of human and managerial capital, as the ability to create various forms of horizontal cooperation increases the value, and 
accordingly, leads to capitalization of local communities and the subject of management. This capitalization is reflected in the fact that the subjects of urban life have greater access to information and resources of subjects interaction as a result of various interaction forms. In the second and third group of cities, respectively, we observe a higher level of either human capital or managerial capital. In the cities of the fourth group the situation of predominant influence of external or objective factors on the territorial development can also be explained in terms of theoretical constructions concerning the assessment of city capitalization.

There is a viewpoint that the high territorial capitalization may have the same negative effect for the city development as the low capitalization (Pereslegin, 2005). And in both cases, the participants of the internal city processes-the public and authorities-have limited influence on the territorial development (Kearney, 2012). Cities with very low territorial capitalization are characterized by passivity of the population in the use of its energy activities within the city. This is manifested, in particular, in labor, cultural, leisure and consumer, daily and seasonal migration to neighboring territories. In this case, the number of inner-life situations that contribute to self-organization of local communities and help to build the interaction mechanisms, is sharply reduced. Within the areas with extremely low capitalization, the local governments are more integrated in the system of state subsidies and are more turned to maintenance of contacts and forms of interaction-but not with the public, but with regional and federal authorities, all this due to the absolute resource constraints.

We noted a large flow of foreign investment in the cities with an extremely high capitalization (recapitalization). In this case, the population activity, as well as the activity of the local self-government bodies in creating various forms of interaction is reduced, being compared to the background activity of large companies and foreign investors. The last, figuratively speaking, can "capture" the city, turning it into an object of profit.

\section{Conclusion}

Thus, the proposed assessment model of the local government activities to manage the processes of socio-economic development of the territory, makes it possible to analyze the willingness of all participants to realize the strategy in an uncertain environment of the municipality. This model of the organizational effectiveness of local governments shifts emphasis from the traditional functional principles of stakeholders' interaction in the development and implementation of strategies to the milieu approach.

The results of the analysis provide the base for elaboration of organizational management models for strategies realization, complex programs for municipal development which are targeted on activation of inside sources of development and on possibilities of local society. Toolset of local authorities' integration in possibilitical milieu is the system for their effort evaluation which includes indicators of readiness of local authorities to organize interaction activating additional sources of municipal development and indicators of local society's readiness for such interaction with the purpose of creation of unique and socially significant values. This model determines correlation between socio-economic development indicators and local authorities' effort on organization of interaction milieu for city's development agents.

These models should be based on the principles of possibilitary interaction-saving the milieu of uncertainty, uniqueness, access to opportunities by mastering the own resources for the territorial development. It is necessary to justify the organizational mechanisms for constructing the internal management processes in the administration bodies of the municipal entities. The biggest theoretical problem in constructing the intra-organization possibilitary processes is developing the mechanisms for integrating the principles of uncertainty and uniqueness of relations into the functional system of organization. These mechanisms allow shifting the emphasis in the activities of administration from the functional and administrative management of the territory to the program-target and scenario techniques.

\section{References}

An, M. (n. d.). Moscow of industrial assembly. Retrieved from http://www.the-village.ru/village/city/estate/ 135993-mihail-an

Brouwer, M. (2000). Entrepreneurship and Uncertainty: Innovation and Competition among the Many. Small Business Economics, 15(2), 149-160. http://dx.doi.org/10.1023/A:1008147829791

Donchevsky, G. N. (2011). Possibilitica, or an art of taking the impossible (essays on technology of indigo era). Moscow: Vusovskaya kniga.

Donchevsky, G. N., Karlina, A. A., \& Ustina, N. A. (2011). Competitive management in the municipal entity: Theory and experience. Modern competition, 4, 81-89. 
Features of regional capital reproduction: Essence, approaches to the assessment, management techniques. (n. d.). In Y. V. Vasilyev (Ed.), Institute of Economics of Karelian Research Centre of Russian Academy of Sciences. Petrozavodsk: Publishing house of the Karelian Research Center.

Interdisciplinary problems of environment approach to the innovative development. (2011). Moscow: Kogito-Tsentr.

Kearney, A. T. (2012). Global Cities Index and Emerging Cities Outlook. Retrieved from http://elordenmundial. files.wordpress.com/2012/12/2012_global_cities_index_and_emerging_cities_outlook_1.pdf/

Khmeleva, G. A. (2012). Human capital as a condition for the formation of innovative regional economy. Samara: SAGMA.

Kleyner, G. B. (2011). Resource theory of an economy system organization. Russian management journal, 9(3), 3-28. Retrieved from http://www.link.springer.com/article/10.1023/A:1008147829791\#page-1

Knight, F. X. (1921/2003). Risks, uncertainty and profit (M. Y. Kajdan, Trans.). Moscow: Delo.

Koenig, H. (2010). The Role of the Public Employee in Citizen Participation. In J. H. Svara, \& J. Denhardt (Eds.), The Connected Community: Local Governments as Partners in Citizen Engagement and Community Building (pp. 120-124). Arizona State University.

Lepskiy, V. E. (2010). In V. E. Lepskiy (Ed.), Reflexive and active environment for innovative development. M.: "Cogito Center". Retrieved from http://www.reflexion.ru/Library/Lepsky_2010a.pdf

Lin, N. (2000). Social Capital: A Theory of Social Structure and Action. NY.

Partushev, V. I. (2008). Basics of a general theory of social technologies. Moscow: IKAR.

Pereslegin. (2005). Capitalization of the future. Russian Expert Review, 2(14), 38-41.

Rifkin, J. (2000). The age of access: How the shift from ownership to access is transforming capitalism. London [etc.]: Penguin books.

Schedrivitsky, G. P. (2003). Organization, leadership and management. Moscow: Nauka.

Schumpeter, J. A. (1964/1995). Capitalism, Socialism and Democracy. Moscow: Ekonomika.

Social Capital: Critical Perspectives. (2000). Oxford.

Stark, D. (2009). The Sense of Dissonance: Accounts of worth in economic life. Princeton, NJ: Princeton University Press.

Tarasov, E. M., Karlina, A. A., \& Ustina, N. A. (2011). Optimization of personnel managerial activities in municipal administration. Problems of Economy and Law, 3, 208-212.

The Decree of Government of Russian Federation (p. 1313). (2008, September 11). Methodological recommendations on grants assignment to municipal formations from the budget of Federal subject of Russian Federation for the purpose of achievement assistant and/or stimulation of attainment of better indicators' values of urban districts and municipal formations" (2008, 28 September). Sobranie zakonodatel'stva RF-Collection of Legislation of the RF, 39.

Turner, J. (2000). The Formation of Social Capital. Social Capital: A Multifaceted Perspective. Washington.

Voytsehovich, V. E. (2011). Formation of a milieu paradigm: From "cogito" of P. Descartes to the creative milieu. In V. E. Lepskiy (Ed.), Interdisciplinary problems of milieu approach to innovation development (pp. 46-51). M.: "Cogito-Center".

Yang, K., \& Callahan, K. (2007). Citizen involvement efforts and bureaucratic responsiveness: Participatory values, stakeholder pressures, and administrative practicality. Public Administration Review, 67(2), 249-264. http://dx.doi.org/10.1111/j.1540-6210.2007.00711.x 


\section{Appendix A}

Table A1. Indicators for analysis of interaction Milieu subjects of municipal socio-economic development

\begin{tabular}{l} 
Indicators Groups \\
\hline \\
Indicators that show readiness of local \\
authorities for organization of interaction \\
activating extra sources of municipal \\
development
\end{tabular}
Indicators
Share of the gross annual value of orders for goods, works and services for
municipal needs in accordance to The list of goods, works and services for
state and municipal needs that are purchased from small business enterprises
$(\%)$
Share of the municipal property that is free from third parties rights, included
to the lists of municipal property for ownership and/or long-term usage by the
small and medium-sized business and organizations, that generates
infrastructure of small and medium-sized business supply (\%)

General value of municipal budget expenditures on development and supply of small and medium-sized business (rubles per each small and medium-sized enterprise)

Total land area provided for building purposes (ha per 10000 people)

Share of municipal budget expenditures in the framework of programs from the total municipal budget expenditures

Total area of business incubators on the municipal territory $\left(\mathrm{m}^{2}\right.$ per 100 small and medium companies)

Amount of provided building permits (units per 1000 people)

Amount of contracts with small business enterprises on a point of order for small business enterprises (units per 10000 people)

Share of municipal autonomous organizations from the total amount of municipal organizations (\%)

Share of finances raised within the framework of target programs by the means of off-budget sources (\%)

Amount of volunteers peacekeepers troops (units per 10000 citizens)

Share of apartment buildings under the management of the house owners association, housing cooperative society etc. (\%)

Level of collection of household payments $(\%)$

Indicators that show organizational Amount of provided licenses for commissioning (units per 1000 people)

readiness of municipal subjects for Competition of the small business requests on tenders for small business interaction and activation of extra sources of municipal development

Indicators that show results of organization of interaction milieu on activation of extra development sources per 1 citizen)

\section{enterprises}

Annual share of new small and medium business subjects which took supply by municipal program of small and medium-sized business supply (\%)

Amount of sales outlets (units per 100 people)

Share of people participating paid cultural and entertaining events organized by local authorities (\%)

Amount of small and medium business subjects per 10000 people

Total value of investments in fixed capital (excluding budgetary funds) (rubles

Monthly average nominal wage (rubles)

Total area of accommodation per 1 citizen (sq. m.)

Annual total area of implemented accommodation per 1 citizen (sq. m)

Share of unprofitable housing and communal service organizations (\%)

Share of tax and non-tax income of local budget from the total value of municipal income (\%)

Share of citizens employed from total amount of citizens who asked for employment assistant in the state placement service (\%)

Migration growth of the population (\%)

Retail trade turnover (rubles per 1 citizen)

People's satisfaction from local authorities activities, including their informational openness ( $\%$ of interviewed people)

Officially registered unemployment rate (\%)

\section{Copyrights}

Copyright for this article is retained by the author(s), with first publication rights granted to the journal.

This is an open-access article distributed under the terms and conditions of the Creative Commons Attribution license (http://creativecommons.org/licenses/by/3.0/). 